\title{
Impact of Global Trends and the Coronavirus Challenge on Consumer Behavior
}

\author{
Lenka Švecová $^{1}$, Galina Ostapenko ${ }^{1,2 *}$ and Jaromír Veber ${ }^{1}$
}

\author{
${ }^{1}$ Department of Economics and Management, University of Chemistry and Technology, Prague, Czech Republic \\ ${ }^{2}$ Department of Management, Masaryk Institute of Advanced Studies Czech Technical University in Prague, Prague, \\ Czech Republic \\ "Corresponding author. Email:galina.ostapenko@cvut.cz
}

\begin{abstract}
The study examines the global trends that have emerged over the last twenty years, such as digitization reflected in e-commerce, sustainable production and consumption, and the latest global challenge coronavirus pandemic to understand their impact on customers' behavior. The study employs qualitative research using content analysis, the secondary analysis of existing statistical data, and the primary research which was conducted among the younger generation in Prague, the Czech Republic in April 2020. Several hypotheses of the study were confirmed, namely: e-commerce-based sales models and sustainable production and consumption, having a sensitive influence on people's consumer purchasing behavior. The coronavirus pandemic will serve as a marker of change for how we will continue to live, produce, and consume in the future. The authors concluded that new attitudes and new behavioral customers' patterns which appeared in a short period of coronavirus quarantine (general swift to online shopping, rational finance spending, a positive trend in purchases of domestic food produced by sustainable agriculture and qualitative labels, successful adaptation to distance e-learning) would most likely change consumer behavior in a long term.

Keywords: E-commerce, Sustainable Consumption, Coronavirus Pandemic, Consumer Behavior
\end{abstract}

\section{INTRODUCTION}

Digitalization changes retail settings [1] and affects the level of customer satisfaction [2]. Extreme development of Internet purchasing is associated with the younger generation growth, known as Millennials (born between 1981 and 1996) and post Millennial Generation - Gen Z (born after 1996) These two Generations are the really global generations connected with social media and Internet. They have the potential to adapt to changing requirements and "the potential for becoming a sustainable lifetime customer” [3].

Partly as a result of consumption patterns, society and businesses are confronted today with sustainability factors, including environmental degradation, carbon emission, climate change, the growing need for renewable sources of energy, and the implementation of a circular economy. The transition to Sustainable Consumption and Production (SCP) is the key element for sustainable development. The European Green Deal and the EU climate actions are the integral parts of this Commission's strategy for implementation the United Nation's 2030 Agenda and the sustainable development goals [4]. As concluded in a study by Gan, et al, (2008) "the production and consumption behavior can directly impact the ecological balance of the environment” [5]. Many researchers (Gupta \& Ogden, 2009; Mozer, 2012) found that many consumers have awareness and preferences to consume green products [6,7], however, as we discovered in our study
(Švecová et al., 2019) the practical implication of new concept of zero waste circular economy in business is low, as well as the awareness of young people to these problems [8]. Therefore, it is important to monitor the dynamic in consumer behavior changes towards sustainable consumption.

Changes in consumer behavior reflected how society and market environments are changing. Customers are becoming more powerful in making their own purchasing decisions. Today, especially in developed countries, the reason for shopping is no longer just the necessary needs, but because it is fun, the goods are cheap enough, they can be different from others in the short term, therefore in the practice of shopping and buying it is often observed the impulse purchasing behavior or over purchasing buying. Impulse purchases represent almost $40 \%$ of all the money spent on e-commerce, while the younger generation (millennials and Gen Z) are more likely to make impulse purchases than any other generation. The so-called emotional marketing strategies emerged, partly in response to the research work by Nobel Prize-winning psychologist Daniel Kahneman (1994), where he augmented that many decision-making questions are "irrationals" [9]. However, under the stressful situation, or during economic crisis and recession the spending behavior change. As usual, stressed consumers increase spending on necessary goods and services, spending less on non-essential items and luxury goods.

The widespread outbreak of coronavirus, which causes the disease COVID-19, is now a global pandemic, and it is a 
real stress situation for businesses and customers. Almost all countries throughout the world are taking precautions to help keep their citizens safe. The Czech Republic has mandated that people wear a cover over their mouths and noses when going out in public, to practice social distancing by limiting their exposure to people outside their household, and closed all non-essential businesses to help stop the spread of the virus. Additionally, schools and universities have stopped face-to-face instruction and are offering online lessons for their students. Following these measures has caused the daily habits of Czech citizens to change. With disruptive impact of coronavirus pandemic on economy and day-to-day lives people care of longerterm consequences. Consumers are shifting their spending habits, becoming more reserved about large and expensive purchases. Some product categories and companies, mostly in e-commerce businesses are growing. In a recent publication by McKinsey \& Co. (2020), it was mentioned that online shopping and home delivery has changed from being a convenience in people's daily lives to necessity [10]. In Accenture's article 'Navigating the impact of COVID-19 in Consumer Goods' it was stated that this ongoing pandemic will permanently alter consumer behaviors that will result in lasting structural changes to the consumer goods industry [11]. In these uncertain times, how long this transition will take remains to be seen, however, it is a good time for researchers to tap into what happens in a consumer landscape across the countries including the Czech Republic. Some habits developed over this period will likely be adopted by citizens when life will be normal.

\section{RESEARCH METHODOLOGY}

Survey methodology was used to test the research questions. The following research questions had been set before the research: RQI: The advent of digitization and related e-commerce is reflected in the growth of sales through e-shops and has an impact on consumer purchasing behavior; RQ2: Sustainability in production and consumption and environmental trends with a product - attribute information (environmental-friendly products, national qualitative brands, national origin of products) have a sensitive influence on consumer purchasing behavior; RQ3: The coronavirus - COVID -19 outbreak is having a very real impact on consumer preferences, attitudes, and behaviors. The research hypotheses: "The new attitudes and new behavioral customers' patterns which appeared in a short period of coronavirus quarantine, would most likely change consumer behavior in a long term".

The methodological tools for examining the research questions and hypotheses were qualitative research using content analysis and secondary analysis of existing statistical data. The primary research of consumer purchasing behavior was conducted in April 2020. The target group was the younger generation (Millennials and Gen Z), most of them were the students of Czech Technical University in Prague. The Questionnaire with 28 questions was constructed to find out the attitudes, preferences, and opinions of young people to contemporary trends and the challenges facing them. We focused on investigating the young people's attitudes and their preferences to on-line shopping; some questions were asked about brand purchase behavior; others were asked to find out the young people's attitudes towards sustainable development and environmental issues. Concerning the coronavirus impact, the questions were proposed to know how the behavior of young people has changed since the beginning of quarantine. The structured questionnaire was formalized by Google Forms and was shared online, so participants could access it. Together 130 respondents were approached, 98 were returned (75,3\%).

\section{ANALYSIS RESULTS}

\subsection{Lessons from Secondary Research}

Online shopping is one of the most popular online activities worldwide with global e-retail sales reaching 3.5 trillion U.S. dollars in 2019. In 2020, the number of digital buyers is expected to be 2.05 billion, which makes $26.28 \%$ of the 7.8 billion people in the world [11]. The Czech Republic is the fastest-growing e-commerce market in emerging Europe. The country has one of the highest numbers of online stores per capita in Europe. The B2C-ecommerce in the Czech Republic increased from 2 billion euros in 2014 to 6,3 billion euros in 2019 with more, that $15 \%$ annual growth rate [12]. The strongest segment of customers shopping through e-shops are young people aged 25-34 years, then the segment in the age category 1624 years, followed by the age group 35-44 years, and at least followed by seniors. About half of the e-shops are connected in some way with physical shops. Online sales are growing much faster than brick-and-mortar sales. About $60 \%$ of respondents in the Czech Republic expect a brick - and - mortar store to have an e-shop. With the coronavirus quarantine period, some conflicting tendencies can be observed in the Czech Republic e-shops. Up to 40 percent of Czech online stores are affected by supply outages from China. Domestic online stores, which sell goods coming directly from China experienced supply disruptions in $70 \%$ of cases. During the quarantine period, more elderly than younger generations started shopping online: young people increased spending by $34 \%$, families by $47 \%$, and the elderly by $52 \%$. On the other hand, the unusual e-shops boom is observed in March and the beginning of April 2020: consumer purchases increased by $44 \%$ compared to the same period of the last year; food product purchases increased by 215\%; pharmacy purchases increased by 286\%. [13].

Exploring the sustainable development issues we focused on current positive signals in SPC, especially agriculture and food. The natural products are intended to provoke great customer customers' interest. The Czech Republic is among the top of the European Union and takes 5th place 
after Austria, Sweden, Estonia, Italy with $14,8 \%$ of the area being organically farmed [16]. The Czech consumers increasingly turning to organic food. However, the share of organic food consumption in the Czech Republic remains very low, at around $1, \%$ of total food consumption in the country, with the average customer spending bellow EUR 12 annually on such products. We noticed in our recent study (2020) that the environmental benefits of organic production have contributed to building a positive consumer attitude towards organic". Based on the analysis of several surveys and statistical information from "Think tank EP", "Eurostat", "Eurobarometer", FIBL, 2019 we discovered that "European consumers appreciate the production with very limited use of pesticides, fertilizers, and antibiotics (79\%), environmentally friendly production (78\%), higher standards for animal care (76\%), higher quality and safety (70\%).” [16]. Organic products can be recognized by their labels, with words organic, eco or bio, the EU organic logo (Euro Leaf).

There are other important labels, certificates and patents, such as powerFrame ${ }^{\circledR}$ patented grid technology and design, sustainable agriculture certificates, offered by UTZ and Rainforest Alliance; RSPO designation for palm oil, produced from organic plantations; SAN / GlOBALG.A. P certification focusing on safety food test (unified in the future), etc. It is important to know the progressive label's recognition by the younger generation, to test their preferences.

The study devoted to changing consumer behavior is partially presented in our recent work [16]. The additional materials and analysis results aimed to investigate the trends in customer behaviour in response to online shopping and sustainable consumption questions are presented below. A great deal of attention was devoted to the study of consumer behaviour of young people during the coronavirus pandemic.

\subsection{Results of Primary Research on Consumer Behaviour of Younger Generation}

The majority of the respondents were young people from Prague. From the results of the survey, we were able to see, that $87 \%$ of our 98 participants were between the ages of 18 and 26 , among whom 58\% were female and $42 \%$ were male. The most important results of this survey can be summarized as follows.

More than $17 \%$ of respondents purchase in e-shops weekly, about half of respondents - per month and the rest of respondents use online shopping for their purchases. That happened is a normal regime, before introducing coronavirus quarantine.

To the question: "What is a big inconvenience to you in a process of online shopping?", 59\% of respondents answered that this is the fact that goods cannot be physically viewed and assessed; for $27,4 \%$ of respondents this is the cost of transport; for $13.7 \%$ of respondents, the big inconvenience is late or missed delivery.
The fact that a physical shop does not have an e-shop is a problem for $20.9 \%$ of respondents. $56 \%$ of respondents answered that it is a problem sometimes and $17.9 \%$ of respondents answered that it is not a problem and it doesn't matter for them. Prospectively, $76.8 \%$ of respondents expect to use e-shops for purchases even in the nearest future, a fifth of respondents do not share this view.

When buying selected foodstuffs (coffee, cocoa, oil, fish, half of the respondents do not solve (not favour) food produced sustainably, two-fifths have opted for this choice, one-tenth is not interested in this topic while shopping. The "Klasa" brand was correctly categorized by almost 2/3 of the respondents as a quality Czech food product brand. This fact shows the growing preferences of younger people for local qualitative brands and products.

3,2 percent of respondents use credit cards to pay for almost all purchases; 23,2 \% use them for payment of three-quarters of their purchases and $20 \%$ use credit cards paying half of all their purchases (see, Figure 1).

Question: How can you estimate the proportion of your credit-card payment in all purchases
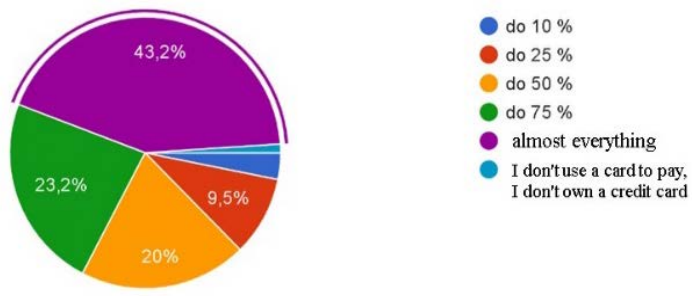

Figure 1. Overview of respondents, using credit-card in their purchasing

The above findings show a general picture of the preferences attitudes and purchasing behavior of young people. The analysis results of how their behavior has changed since the beginning of quarantine are presented below.

\subsection{Understanding the short-term and potential long-term impact of COVID-19 on consumer behavior}

Respondents in Prague change their behavior: they avoid crowded places, they are self-isolating, they canceling trips abroad. They purchase extra food and cleaning supplies, they spend less money on big purchase and expensive goods; they use only non-cash payment and tremendously increase online purchasing. During coronavirus quarantine period about $60 \%$ of respondents reported that they have used online shopping to purchase clothing, food and electrical goods (50\%, $41,5 \%$ and $35 \%$ of respondents respectively), followed by drugstores and goods for home. (see Figure 2). 
Question: I used the e-shop during the coronavirus period

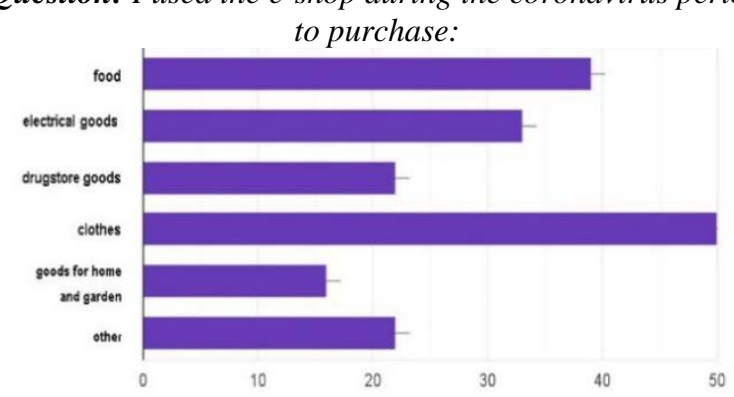

Figure 2. Overview of on-line shopping purchases during coronavirus period

Almost $65 \%$ of respondents reported that they strongly or somewhat agree that companies should suspend their normal production to help product essential supplies.

To purchase food online they used online stores with delivery, 29\% used rohlik.cz and 19\% used kosik.cz.

When asked about what services offered by grocery and retail stores they value most, about $50 \%$ of our respondents said that they most value the designed hours to service senior customers. To purchase food online many respondents used online stores with delivery: 29\% used rohlik.cz and 19\% used kosik.cz. More than 30\% of respondents said that they also value permanent behavior shifts to online and delivery across customer segments. 80\% of respondents strongly or somewhat agree that brands and companies should offer flexible payment terms. This measure could help many people that are worried about their finances right now and it could also help the economy because it could encourage them to buy more. When we asked about changing behaviour during coronavirus and the possibility of its adopting them in the future, $12.5 \%$ of respondents think that consumer behavior has been forced to immediately change, and change on a massive scale, while $62.5 \%$ somewhat agree and believe that the biggest change will be a general switch to online shopping.

Question: Do you agree that consumer changing behavior during the coronavirus period can be adapted by them in the future

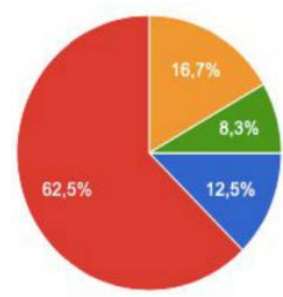

Strongly agree (Consumer behavior has been forced to immediately change, and change on a massive scale)

Somewhat agree (General switch to online shopping.)

Neither agree nor disagree

Somewhat disagree (Limiting factor for businesses will be the level of readine.

Strongly disagree (Nothing will change radically)

Figure 3. Understanding the behavior during coronavirus period and long-term consequences

Almost $75 \%$ think that with adaptation to coronavirus COVID-19 customer behavior change; respondents expect their behavior and preferences to on-line shopping purchases, to e-learning and sustainable consumption arose with adaptation to the coronavirus will remain in the distant future. We should have added here, that according to our survey respondents felt by themselves very comfortable with distance online and distance learning. Throughout history, the spread of disease and economic crisis has been linked to lower emission. Pollution and greenhouse emissions have fallen not only in the Czech Republic but across continents as countries try to contain the spread of new coronavirus. We asked if our respondents agree that coronavirus will have a lasting impact on carbon emissions.

Question: Are you agree that coronavirus COVID-19 will have a lasting impact on carbon emission.
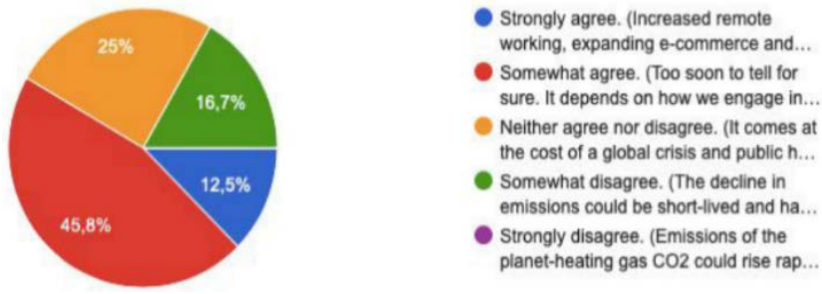

Figure 4. Overview of lasting impact of coronavirusCOVID-19 on carbon emission

Figure 4 above shows, that $12.5 \%$ of our respondents strongly agree because, for example, increased remote working, expanding e-commerce and shrinking supply chains, reduction in air travel, if those changes become permanent, it could make a substantial contribution to the reduction of global carbon emission. Almost 45.8\% somewhat agree but they think that it is too soon to tell for sure. $25 \%$ neither agree nor disagree and they thought that it comes at the cost of a global crisis and public health emergency and it won't really affect future emissions. Almost $16.7 \%$ of respondents somewhat disagree. According to their opinion the decline in emissions could be provisional, and have little impact on the concentrations of carbon dioxide.

\section{CONCLUSION}

Today and in the near future the share of e-shop purchases will continue to increase, and the segmentation will undoubtedly increase purchases of groceries, ready meals, and medicines over the internet. Consumer behavior will likely change after the quarantine period, generally shifting to online shopping.

The digital world of generation $\mathrm{Y}$ and $\mathrm{Z}$ has helped to adopt quickly measures of restrictions, social distancing, spending a lot of time with digital activities, and on-line learning. During the coronavirus period, an important behavioral trend in sustainable consumption was manifested. The consumers preferred to consume healthy, safety and sustainable products and services.

"Buy local" trend accelerates; new companies and product categories are growing. The native Czech brands as Krasa, Rochlik, Košik are becoming increasingly popular among 
Czechs. Among the younger generation, a positive trend in purchases of domestic food produced can be expected.

As coronavirus-COVID-19 is more than a health crisis, but a social and economic crisis, it might have a prolonged impact on buying and spending behaviors. At least during the period of economic recovery people will continue to show the new behavior patterns, namely: saving money and avoiding spending money frivolously; shopping more cost consciously and buying more sustainable options; preferring to buy more products for health and well-being. Therefore, it could be predicted over this period the less impulse buying or overbuying being done by consumers and increasing shift towards proactive consumer behaviour. These conclusions are linked with Neilson's Insights study of 6 stages of behaviors during coronavirus from the stage of "proactive health-minded buying" to the stage of "living a new normal” [18].

We are convinced that some habits and consumer behaviors developed over this period will be adopted by citizens and first of all by younger generations when things eventually return to normal. The new findings of the primary survey are beneficial to marketers and companies to be more successful in the future during and after this pandemic.

\section{REFERENCES}

[1] G. Ritzer, J. Nathan, "Production, consumption, presumption: the nature of capitalism in the age of the digital 'prosumer". Journal of Consumer Culture, 10, no.1 (March 2010):36. doi:10.1177/1469540509354673

[2] I. Poncin, M.M.Ben, “The impact of "eatmospherics” on physical stores”. Journal of Retiling and Consumer Services, 21. Issue 5 (September 2014): 851-856. doi: 0.1016/j.jretconser.2014.02.013

[3] C.A. Martin, A.J. Bush, "Do role models influence teenagers’ purchase intentions and behavior?”. Journal of Consumer Marketing, 17, no. 5, (September 2010), pp. 441- 453.

[4] European Commission. Communication from the Commission to the European Parliament, the European Council, the Council, the European Economic and Social Committee and the Committee of the Regions. “The European Green Deal”. Brussels (December 11, 2019). COM (2019) 640 final.

[5] C.W. Gan, L. Ozanne, L, T. Kao, “Consumers’ purchasing behavior towards green products in New Zeeland”. Innovative Marketing,4, no.1 (May 2008), pp. 92-102.

[6] Gupta, S and Ogden, D. T. "To buy or not to buy? A social dilemma perspective on green buying”. Journal of Consumer Marketing, 26, no.6. (January 2009): 376391. doi:10.1108/07363760910988201.

[7] Mozer, Andrea K. (2012). Thinking green, buying green? Drivers of pro-environmental purchasing behavior. Journal of Consumer Marketing 32 (3), 167175. https://doi.org/10.1007/978-3-642-21455-4_3

[8] L. Švecová, G. Ostapenko, J. Veber, Y.Valeeva. "The Implementation Challenges of Zero Carbon and Zero Waste Approaches”. E3S Web of Conferences Journal,124 (25 October 2019)": doi:10.1051/e3sconf/201912404025

[9] D. Kahneman, "New challenges to the rationality assumption. Journal of Institutional and Theoretical Economics, 150. no1. (March,1994), pp. 18-36.

[10] R. Diebner, E. Silliman, K. Ungerman, M. Vancauwenberghe, “Adapting customer experience in the time of coronavirus” McKinsey \& Company. Marketing and Sales Practice (April 2020).

[11] Accenture. "Navigating the impact of COVID-19 in Consumer Goods”, (4 April, 2020).

[12] Statista 2020. "E-commerce share of total retail sales worldwide 2014-2023”, published by J. Clement. (August30,2020).

[13] The size of the e-commerce market in the Czech Republic. In: https://www.ceska-ecommerce.cz/.

[14] Slovenská Spořitelna CZ. "Household expenditures fell by almost a quarter” Instant Comment [6 April,2020].

[15] European Union Statistics/ Eurostat. Organic farming statistic. In:

https://ec.europa.eu/eurostat/statistics-2018.

[16] L. Švecová, G. Ostapenko, J. Veber, "Digitalization, sustainable development, coronavirus and consumer behavior change”. In: 28th Interdisciplinary Information Management Talks. 2020 Gerhard Chroust, Linz, Österreich, pp.187-194.

[17] The Nielsen Company Insights. In: https://www.nielsen.com/us/en/insights/article/2020/ke y-consumer-behavior-thresholds-identified-as-thecoronavirus-outbreak-evolves/ US, March 10,2020. 